Research Article

\title{
Experimental Study on the Mechanical Behavior of Yunnan Limestone in Natural and Saturated States
}

\author{
Xutao Zhang $\mathbb{D}^{1}{ }^{1}$ Mingyang Ren $\mathbb{D}^{2},{ }^{2}$ Zhaobo Meng, ${ }^{1}$ Baoliang Zhang, ${ }^{1}$ and Jinglong $\mathrm{Li}^{3}$ \\ ${ }^{1}$ School of Architecture and Engineering, Liaocheng University, Liaocheng 252059, China \\ ${ }^{2}$ School of Civil and Transportation Engineering, Henan University of Urban Construction, Pingdingshan, Henan 467036, China \\ ${ }^{3}$ School of Civil Engineering, Shandong University, Jinan, Shandong 250061, China
}

Correspondence should be addressed to Xutao Zhang; zhangxutao@lcu.edu.cn

Received 6 November 2020; Revised 3 February 2021; Accepted 15 February 2021; Published 28 February 2021

Academic Editor: Gang Zhou

Copyright ( $\odot 2021$ Xutao Zhang et al. This is an open access article distributed under the Creative Commons Attribution License, which permits unrestricted use, distribution, and reproduction in any medium, provided the original work is properly cited.

Rock material is a kind of mineral assemblage with complex structural heterogeneity, whose mechanical behavior is strongly affected by water or moisture content. In this work, we carried out a series of laboratory tests to investigate the mechanical response (e.g., deformation, strength, and failure characteristics) of Yunnan limestone in natural and saturated states. Our test results show that (1) after saturation, the stiffness and strength of Yunnan limestone degenerate considerably. Compared with the natural condition, the elastic modulus, deformation modulus, and tensile modulus decrease by about $30 \%$ on average, and uniaxial compressive strength and tensile strength also decrease by about $15 \%$ and $20 \%$, respectively. While Poisson's ratio is less affected by water content, it can be regarded as a constant; (2) the elastic modulus and deformation modulus of Yunnan limestone are significantly affected by confining pressure, and the relationship between them and confining pressure satisfies the law of hyperbolic function; (3) the peak strength envelope of Yunnan limestone has significant nonlinear characteristics, which can be well described by generalized Hoek-Brown strength criterion. However, the generalized Hoek-Brown criterion does not apply to the residual strength, which shows a linearly increasing trend with the increasing confining pressure; (4) the failure modes of Yunnan limestone are significantly dependent on confining pressure but insensitive to water content. With the increasing confining pressure, the failure modes of Yunnan limestone transform from splitting failure, tension-shear mixed failure, single inclined plane shear failure to $\mathrm{Y}$-shaped or X-shaped conjugated shear failure. The test results can provide important experimental data for the establishment of the constitutive model of Yunnan limestone, which will contribute to obtain more reliable results for stability assessment of Xianglu Mountain Tunnel.

\section{Introduction}

A reliable estimate of rock mass characteristics (i.e., strength and deformation) is of primary importance for theoretical calculation and engineering design $[1,2]$. At present, some scholars have proposed many methods to accurately predict the mechanical properties of rocks $[3,4]$. However, the rock masses encountered in practical engineering always exist in certain groundwater environments. A large number of experimental studies and engineering practices have demonstrated that a small increase in water content may lead to a marked reduction in strength and deformability of rock [5-9]. This effect is more pronounced in fine-grained sedimentary rocks, particularly in sandstone and limestone.
Due to the weakening effect of water on rock mechanical properties, the stability and safety of surrounding rock are greatly reduced, which brings a great threat to the construction and safe operation of underground engineering. So, it is of great significance to investigate the influence of water content on rock mechanical properties for the stability evaluation of underground engineering and the design of supporting structure.

Currently, many studies have been performed to investigate the effect of water saturation on the mechanical behavior of rocks experimentally [10]. Chen and Zhou [11] adopted MTS-815 electrohydraulic servo test system to carry out uniaxial compression tests on sandstone, granodiorite, limestone, and marble with different saturation levels and 
studied the variation of uniaxial compressive strength with water saturation. The results showed that the peak strength of rock decreased rapidly with the increase in water saturation. When the water saturation reaches a certain value, the peak strength of the rock is basically stable. Based on the tests on 15 sandstones from the UK, Hawkins and Mcconnell [12] found that the relationship between the uniaxial compressive strength and water content satisfies a law of negative exponential function. Wang et al. [13] conducted a series of direct shear tests on red sandstone and obtained a good logarithmic relationship between cohesion, internal friction angle, and water content. Xiong et al. [14] employed RMT-150B rock mechanics test system to conduct laboratory tests on sandstone, sandy mudstone, and mudstone under natural and saturated conditions and found that the sensitivity of peak strength to the confining pressure in the water-saturated state is greater than that in the natural state. Roy et al. [15] experimentally investigated the fracture and mechanical properties of saturated sedimentary rocks, and the results indicated that the Brazilian tensile strength and fracture toughness generally decrease with increasing saturation levels, and a linear relationship exists across all the saturation values. Li et al. [16] performed shear creep tests on dry and saturated sandstones, and test results showed that water could enhance creep strain and creep strain rate while decreasing the creep rupture strength.

To study the correlation between rock deformation characteristics and water content, Erguler and Ulusay [17] conducted groups of laboratory tests on different types of clay-bearing rock collected from various parts of Turkey and developed a method for estimating the rock deformability at any water content based on physical properties. Shao et al. [18] performed experimental research on the elastic wave velocity and mechanical property of sandstone from Longyou grottoes under different water contents and found that elastic modulus decreases exponentially with the increase in water content, while the elastic wave velocity decreases abnormally to a very low value at the water content of about $1.5 \%$ due to expansible clay minerals. Yu and Peng [19] carried out a range of compression experiments on chlorite schist under dry and saturated conditions and discussed the effect of water content on deformation characteristics. Guo et al. [20] studied the influence of water saturation on mechanical properties and energy mechanism of karst limestone by laboratory experiment and found that saturation has a significant softening effect on the elastic modulus of karst limestone.

Besides, many scholars have also studied the softening mechanism and failure mode of rocks after water absorption. Hadizadeh and Law [21] studied the softening process of sandstone by water and found that the microstructure characteristics of rock, such as the geometric size of pores, the existence of clay minerals, and the contact of particles, play a key role in controlling the influence of physicochemical action of pore water on rock strength. Yang et al. [22] measured the change of water absorptions, contact angles, microstructures of the minerals, porosities, and strength of slates in different absorption by scanning electron microscopy and the triaxial compression experiment and concluded that the capillary force and surface tension between mineral particles would decrease after water absorption, which leads to the decrease of internal cohesive force. Han and Zhou [23-25] analyzed the pore structure of different metamorphic coals by the Mercury intrusion method and the nitrogen adsorption method. Huang and Che [26] investigated the microstructure characteristics of mudstone in different saturation states through scanning electron microscopy and X-ray diffraction analysis. The results showed that the reason for mudstone softening is that the cementation connection between particles is destroyed under the action of water, leading to the change of rock structure from compact structure to loose irregular loose floc structure. Meng et al. [27] studied the failure mode of sedimentary rock under different water contents and found that the failure mode of rock is mainly brittle and shear failure under dry conditions, with marked strain-softening characteristics. With the increasing water content, the failure mode transforms into plastic failure, and the strain softening is not significant.

Although researchers have done extensive efforts to investigate the influence of water content on the strength and deformation characteristics of rocks, there are still some shortcomings. For instance, in the aspect of rock strength, most of them focus on the relationship between water content and uniaxial compressive strength or the relationship between water content and Mohr-Coulomb strength parameters (cohesion and friction angle). Few studies have been done on the effect of water content on postpeak residual strength. In fact, with the development of underground engineering technology, more and more deep underground projects have emerged. After excavation, the high ground stress is released instantaneously, which often leads to the surrounding rock in the postpeak state. Moreover, a large number of studies have shown that the strength of deep rock often satisfies the nonlinear law such as the Hoek-Brown criterion, while the linear Mohr-Coulomb criterion is not applicable [28-31]. As for the deformation characteristics, the current researches are mainly based on the influence of the water content on the elastic modulus of the rock. However, the mechanical parameters that characterize rock deformation characteristics also include deformation modulus and tensile modulus. There are very few studies on tensile modulus in particular. This is the reason that the Brazilian splitting test is difficult to accurately obtain the tensile modulus of the rock [32].

In view of the shortcomings of the current research, we take Xianglu Mountain Tunnel of Yunnan Water Diversion Project in China as the engineering background and conduct a series of laboratory experiments to investigate the mechanical characteristics of Yunnan limestone under natural and saturated conditions. The elastic modulus, deformation modulus, tensile modulus, peak and residual strength, and tensile strength are measured for natural and saturated states. Additionally, the quantitative relationships between the mechanical parameters and confining pressure are given for natural and saturated Yunnan limestone by applying the regression analysis method. Finally, the failure mechanism and failure mode of Yunnan limestone and the applicability 
of the generalized Hoek-Brown strength criterion to Yunnan limestone are discussed in detail.

\section{Experimental Design}

2.1. Description of Rock Samples. As shown in Figure 1(a), the Yunnan Water Diversion Project, with a total length of $663 \mathrm{~km}$, is situated in the southwest of China. Xianglu Mountain Tunnel is located in the first section of the water conveyance route. The stratum lithology and geological conditions along the Xianglu Mountain Tunnel are very complex, and the tectonic action is strong $[33,34]$. There are many large faults along the line, and the stability of the surrounding rock is poor. The rock specimens used throughout this study were retrieved from the limestone strata with a depth of about $-1000 \mathrm{~m}$ at DLZK38 + 00 (see Figure 1(b)). The drilled Yunnan limestone is weak to slightly weathered with fine texture and no obvious defects. According to mineral mirror identification and chemical composition analysis, the main mineral components include calcite with content greater than $96 \%$ and quartz with content less than $4 \%$.

The rock samples retrieved from the engineering field were first cut and cored into cylindrical specimens. Then the ends of treated specimens were finely ground and polished to meet the specifications recommended by ISRM, i.e., standard rock specimen with a height of $100 \mathrm{~mm}$ and diameter of $50 \mathrm{~mm}$, satisfying the ratio of height to diameter of $2: 1$. Some prepared limestone specimens are shown in Figure 2. It can be seen that Yunnan limestone is grey, and there are no visible macrocracks on the surface of all rock specimens.

2.2. Testing Apparatus. In this study, the adopted apparatuses include RLW-2000 rigid servo rock mechanical test machine (for uniaxial compression test and conventional triaxial compression test) and microcomputer-controlled electronic universal test machine (for the direct tensile test), as shown in Figure 3. The maximum loading capacity of the RLW-2000 rigid servo rock mechanical test machine is $2000 \mathrm{kN}$, and the maximum confining pressure is $60 \mathrm{MPa}$. The axial and radial strains of the rock specimen were measured with axial LVDT and radial LVDT (see Figure 3(b)), respectively. The microcomputer-controlled electronic universal test machine has a maximum axial loading capacity of $100 \mathrm{KN}$ with an accuracy of $0.5 \mathrm{kN}$. Due to its inherent defects, the tensile strength obtained indirectly by the Brazilian splitting test is often inaccurate. Furthermore, it is also difficult to obtain the tensile modulus [32]. For the sake of measuring direct tensile strength and tensile modulus accurately, the self-developed fixture [35] used in direct tensile tests is shown in Figure 3(d), which is bonded to the end of the specimen with special strong glue.

2.3. Testing Procedures. To investigate the mechanical properties of Yunnan limestone in the saturated state, the vacuum saturation device shown in Figure 4(a) is adopted.
According to CRTHWCE (Code for Rock Tests of Hydroelectric and Water Conservancy Engineering, SL264-2007) standards [36], the specimen should be dried for 24 hours at a temperature of $105^{\circ} \mathrm{C}$ in the drying box (see Figure 4(b)) before water saturation. Then, the dry specimen was taken out and weighed. Next, the dry specimens were divided into two groups. One group was placed at room temperature to reach the natural moisture state. For the other group of specimens, they were put into a vacuum saturator and saturated at $-0.1 \mathrm{MPa}$ air pressure. During this period, the weight of the specimen is measured until it does not change. At this time, it can be considered that the specimen has reached the corresponding natural state and fully saturated state.

In terms of the measured geostress data, the maximum principal stress of rock mass for Xianglu Mountain Tunnel is about $34 \mathrm{MPa}$, so five confining pressure levels are determined for the conventional triaxial compression test, which are $0 \mathrm{MPa}, 10 \mathrm{MPa}, 20 \mathrm{MPa}, 30 \mathrm{MPa}$, and $40 \mathrm{MPa}$, respectively. According to the suggested testing method specified by CRTHWCE standards [36], the first step of the triaxial compression test is to apply hydrostatic pressure at a loading rate of $0.1 \mathrm{MPa} / \mathrm{s}$ until the required confining pressure is reached. After that, the confining pressure keeps constant, while the axial stress continues to increase. To obtain the complete stress-strain curve including the postpeak stage, the loading mode of axial stress is switched to displacement controlling mode with a rate of approximately $0.001 \mathrm{~mm} / \mathrm{s}$ when the stress level is close to the peak strength. For the direct tensile test, the tensile specimen is first fixed in the puller of the universal test machine with the tensile fixture. Then, the axial tensile stress was continuously applied in displacement controlling mode with a rate of $0.002 \mathrm{~mm} / \mathrm{s}$ until the specimen is pulled to fracture. To avoid the errors caused by the discreteness of the limestone specimens, each test case was repeated by three specimens, respectively. Thus, the final test data is an average value of these three specimens. In this study, the specimen number is labeled according to the water content state, test type, and confining pressure magnitude. For example, the labels A-C-10-1 and B-C-101 denote the first specimen for triaxial compression tests with confining pressure of $10 \mathrm{MPa}$ in the natural state and saturated state, respectively. Similarly, the labels A-T-2 and $\mathrm{B}-\mathrm{T}-2$ represent the second specimen for direct tensile tests under natural and saturated conditions, respectively.

\section{Experimental Results Analysis}

3.1. Water Absorption Capacity and Porosity. Table 1 lists the mass of all specimens in the dry state, natural state, and saturated state. Through the statistical analysis, the average dry density, natural density, and saturated density of Yunnan limestone are $2.640 \mathrm{~g} / \mathrm{cm}^{3}, 2.642 \mathrm{~g} / \mathrm{cm}^{3}$, and $2.653 \mathrm{~g} /$ $\mathrm{cm}^{3}$, respectively. Compared with the dry state, the density of Yunnan limestone in its natural state does not increase much, but the density increases significantly after being saturated with water. In addition, the average natural water content and saturated water content of Yunnan limestone 


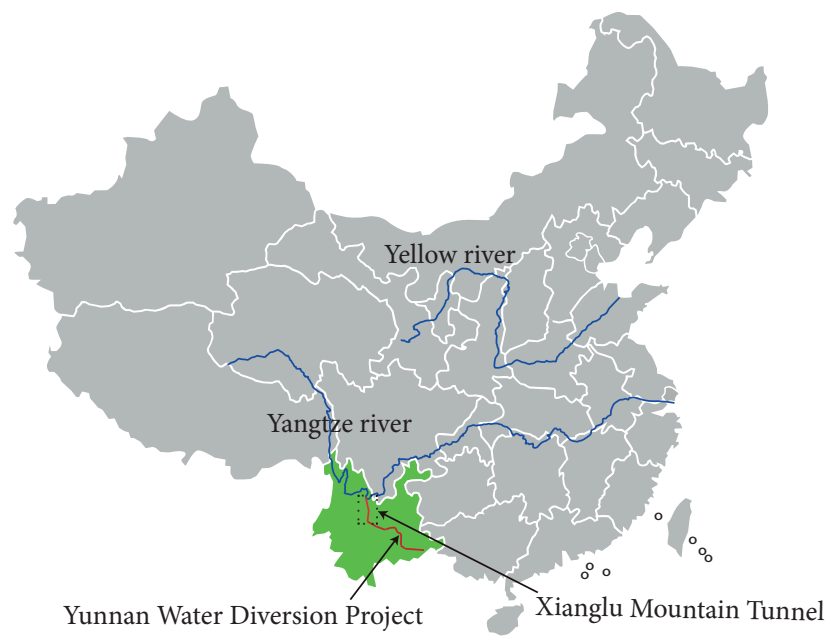

(a)

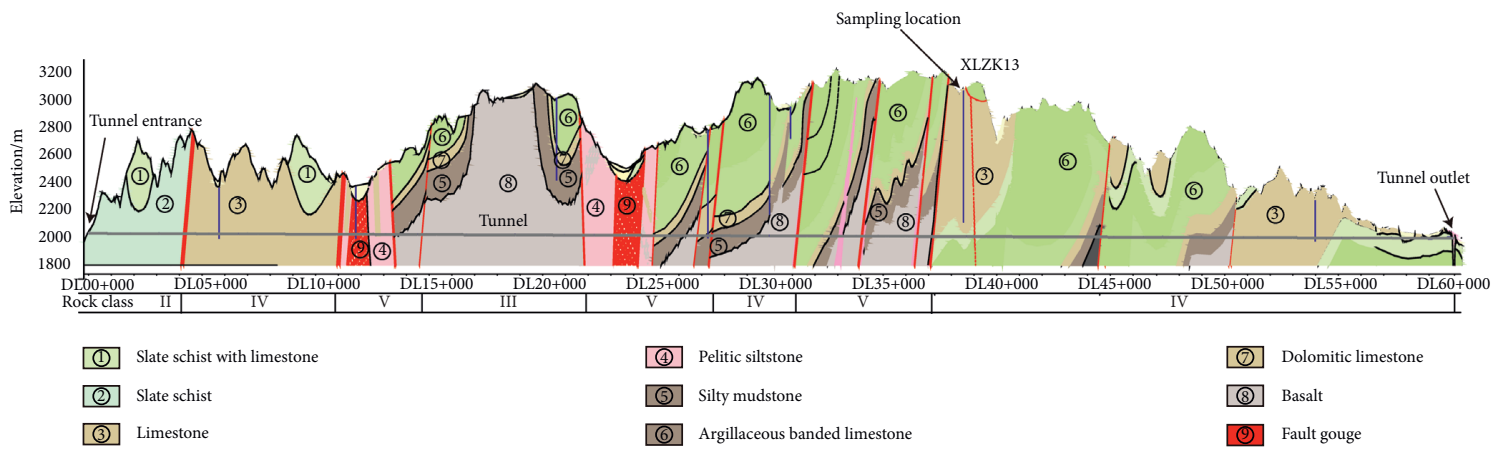

(b)

Figure 1: (a) Location of Yunnan Water Diversion Project and (b) geological profile of Xianglu Mountain Tunnel.

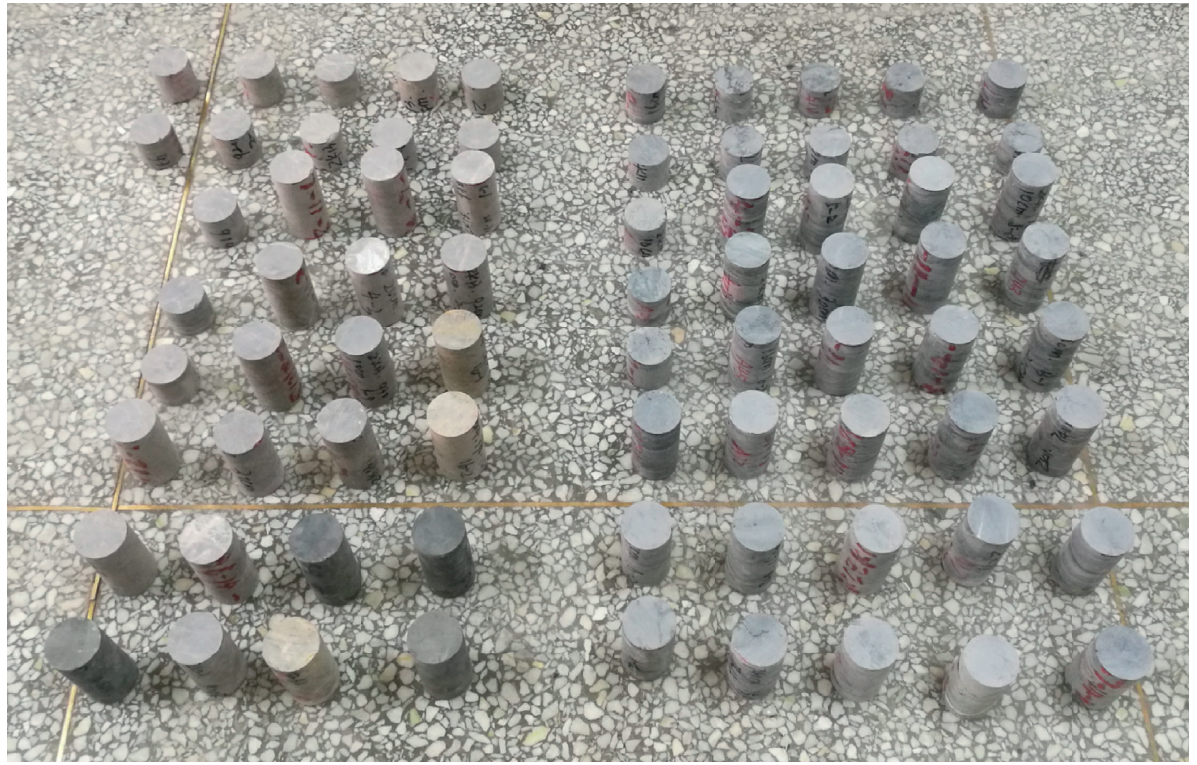

(a)

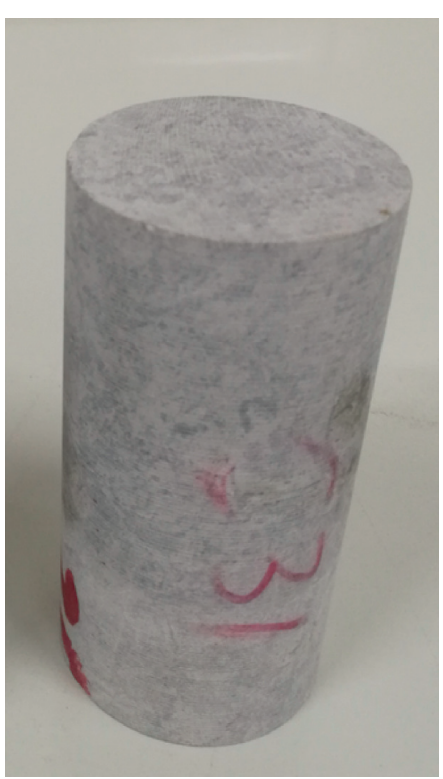

(b)

FIGURE 2: Prepared rock specimens. (a) Standard specimens. (b) Typical Yunnan limestone. 


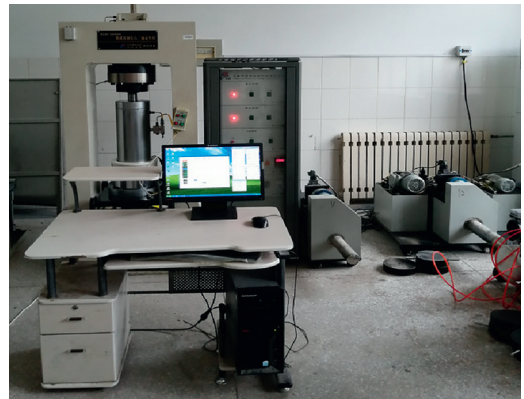

(a)

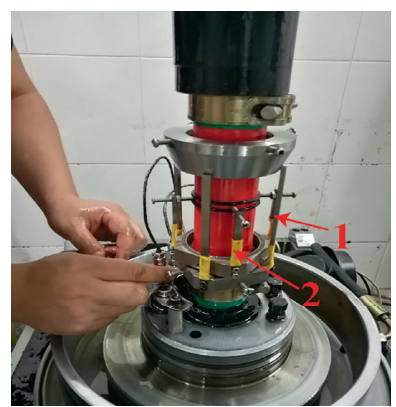

(b)

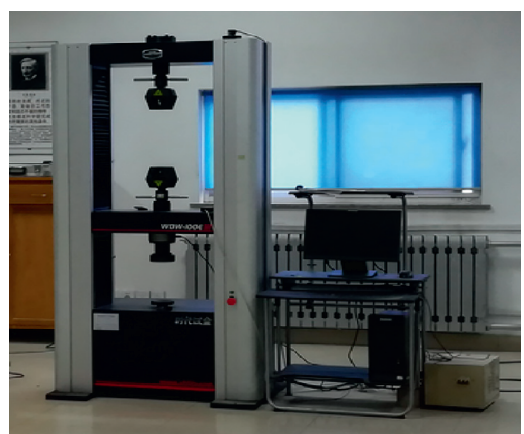

(c)

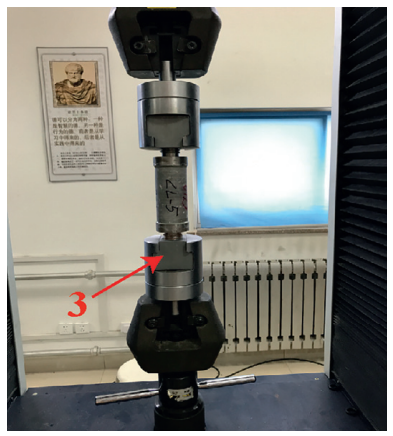

(d)

FiguRE 3: Testing apparatus. (a) RLW-2000 rigid servo rock mechanical test machine. (b) Specimen for conventional triaxial compression. (c) Microcomputer-controlled electronic universal test machine. (d) Specimen for direct tensile test. 1-axial strain sensor. 2- radial strain sensor. 3- fixture used for direct tensile test.

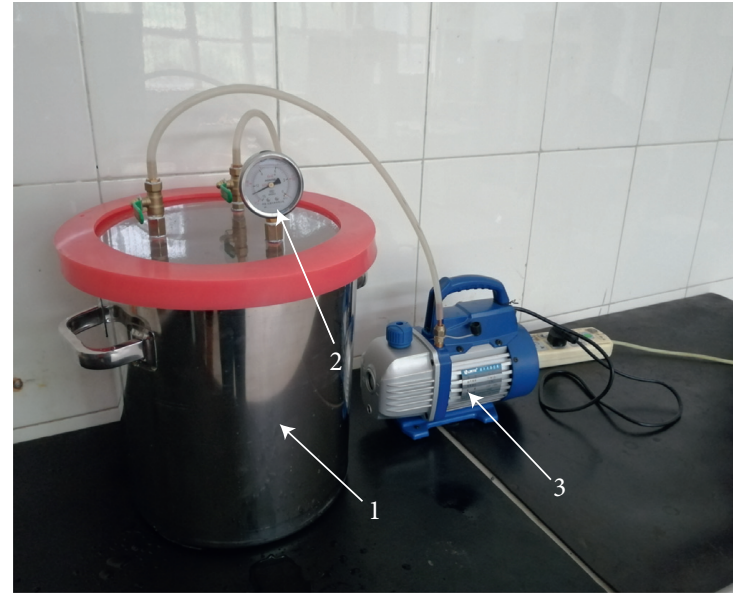

(a)

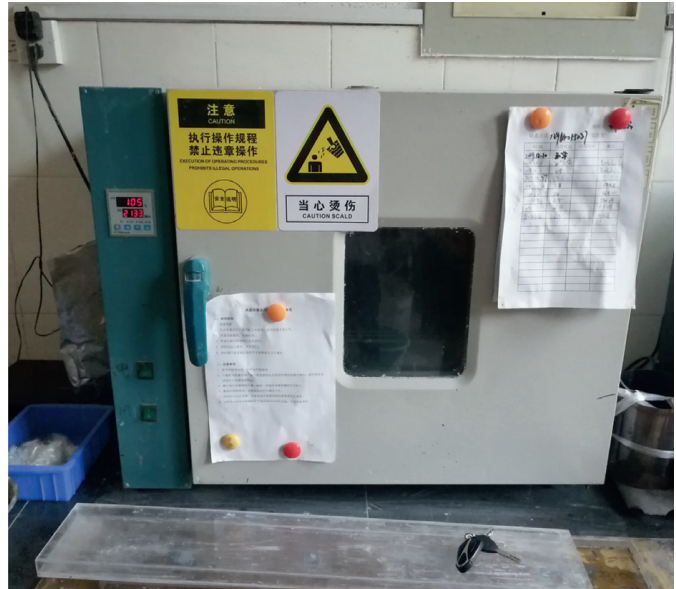

(b)

Figure 4: Saturation and drying device. (a) Vacuum saturator. (b) Drying box. 1- Saturating cylinder. 2- Vacuum pressure gauge. 3-Vacuum pump.

are $0.1 \%$ and $0.5 \%$, respectively. Therefore, it can be seen that the water absorption capacity of Yunnan limestone in its natural state is relatively small, far less than the water absorption capacity in the vacuum saturation state, which is only about $15 \%$ of the latter.

Assuming that the voids of the saturated specimen are all filled with water, the porosity of Yunnan limestone can be calculated according to the following equation:

$$
n=\frac{4\left(m_{s}-m_{d}\right)}{\rho_{w} \pi d^{2} h},
$$

where $m_{s}$ and $m_{d}$ are the mass of the same specimen in saturated state and dry state, respectively; $\rho_{w}$ is the density of water; $d$ and $h$ are the diameter and height of the specimen, respectively. 
TABLE 1: Mass of all specimens in the dry state, natural state and saturated state.

\begin{tabular}{lccc}
\hline Specimen number & $\begin{array}{c}\text { Mass of specimen in } \\
\text { dry state }(\mathrm{g})\end{array}$ & Mass of specimen in natural state $(\mathrm{g})$ & Mass of specimen in saturated state $(\mathrm{g})$ \\
\hline A-C-0-1 A-C-0-3 & 518.55 & 519.07 & 519.07 \\
A-C-10-1 A-C-10-3 & 518.55 & 518.09 & 518.56 \\
A-C-20-1 A-C-20-3 & 517.57 & 517.91 & 520.03 \\
A-C-30-1 A-C-30-3 & 518.04 & & 520.59 \\
A-C-40-1 A-C-40-3 & 517.39 & & 521.36 \\
B-C-0-1 B-C-0-3 & 517.44 & & 520.20 \\
B-C-10-1 B-C-10-3 & 518.00 & & 520.78 \\
B-C-20-1 B-C-20-3 & 518.77 & 518.41 & \\
B-C-30-1 B-C-30-3 & 517.62 & & 521.15 \\
B-C-40-1 B-C-40-3 & 518.19 & 518.52 & 520.68 \\
A-T-1 A-T-3 & 517.89 & 518.56 & \\
B-T-1 B-T-3 & 518.05 & & \\
Average value &
\end{tabular}

Note. A represents the specimen in the natural state; B represents the specimen in the saturated state; C stands for compression test; $D$ stands for the direct tensile test; $0,10,20,30,40$ represent different confining pressures, respectively.

Combining Table 1 and equation (1), the average porosity of Yunnan limestone can be calculated to be $1.32 \%$, which far less than the average porosity (13\%) of limestone. It indicates that the Yunnan limestone has less porosity and belongs to relatively dense rock.

3.2. Deformation Characteristics. Since there are many stress-strain curves obtained from the triaxial compression test and uniaxial compression test, only typical stress-strain curves are selected as shown in Figure 5. The level of confining pressures ranges from $0 \mathrm{MPa}$ (uniaxial compression test) to $40 \mathrm{MPa}$. Under uniaxial compression, the stress-strain curve can be divided into four stages: initial deformation stage (OA), linear elastic deformation stage $(\mathrm{AB})$, strain-hardening stage (BC), and stress drop stage (CD). The initial deformation stage is also known as the crack closure stage, and the stress-strain curve is up concave due to the closure of existing microcracks in this stage. As the axial stress increases gradually, the microcracks are completely closed and the axial stress increases linearly with the increasing axial strain. When the axial stress exceeds the yield stress, the microcracks in the specimen begin to germinate and propagate gradually. Simultaneously, the rock stiffness decreases slowly, which leads to the occurrence of strain hardening. Once the peak stress is reached, the stressstrain curve drops rapidly to zero, accompanied by a violent sound. So, the failure of rock under uniaxial compression presents a high brittleness, and there is almost no residual strength.

When confining pressure is not less than $10 \mathrm{MPa}$, the stress-strain curves of Yunnan limestone can be roughly divided into five stages: initial deformation stage $\left(\mathrm{OA}^{\prime}\right)$, linear elastic deformation stage (A'B'), strain-hardening stage ( $\left.B^{\prime} C^{\prime}\right)$, stress drop stage (C'D'), and residual stress stage (D'E'). In addition, the lower the confining pressure is, the more remarkable the initial deformation stage is. With the increasing confining pressure, the initial deformation stage gradually disappears, and the strain-hardening and brittleductile transitions are more and more significant. On the whole, under uniaxial compression, the stress-strain curve exhibits an elastic-brittle trend. In contrast, the stress-strain curve presents an elastic-plastic softening-ideal plastic trend with the increase of confining pressure. Therefore, it can be concluded that confining pressure has a great influence on the shape of the stress-strain curve. By comparing the stressstrain curves of Yunnan limestone under two water content conditions, it can be found that the stress-strain curves between natural state and saturated state are similar, which implies the effect of water content on the shape of the stressstrain curve of Yunnan limestone is not remarkable.

Figure 6 displays the stress-strain curves from direct tensile tests under natural and saturated conditions. It is clearly seen that the shape of the tensile stress-strain curves of Yunnan limestone under two water content conditions is basically identical, although the tensile strength of saturated rock is low. On the whole, the tensile stress-strain curve can be roughly divided into three stages: stress slowly increasing stage, stress linearly increasing stage, and stress sharply decreasing stage, which corresponds to the OA segment, $\mathrm{AB}$ segment, and BC segment in Figure 6, respectively. In the first stage, the tensile stress-strain curve presents an evident nonlinear rise trend, which is similar to the initial deformation stage of the stress-strain curve from the uniaxial compression test. However, unlike the closure mechanism of microcracks, the deformation during this stage mainly includes two parts. One is the deformation of the strong glue, which bonds the fixture and end of the specimen. The other is the deformation of connection between the testing machine, fixture, and specimen. When the deformations of these two parts are completed, the tensile stress increases linearly with the increasing strain. Once the peak tensile stress is reached, the specimen is fractured directly, and the stress-strain curve immediately drops to zero. Compared 


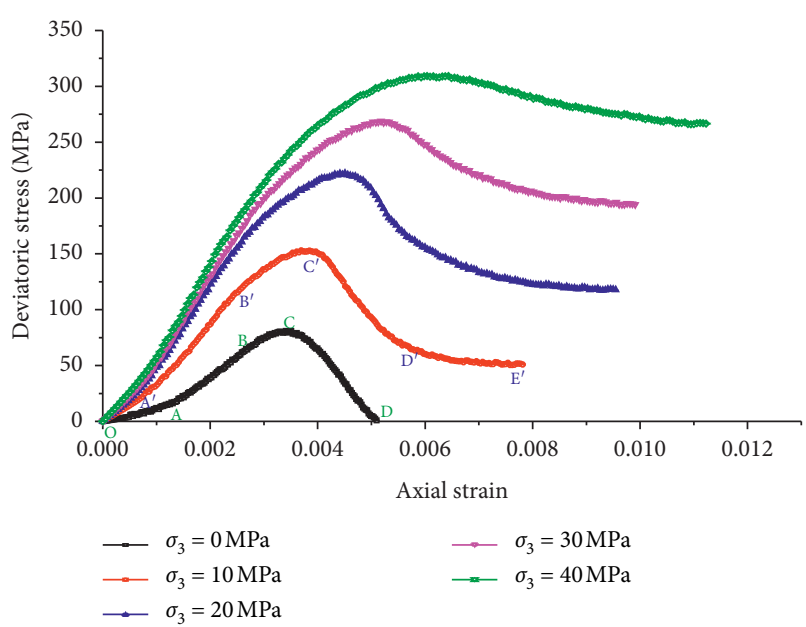

(a)

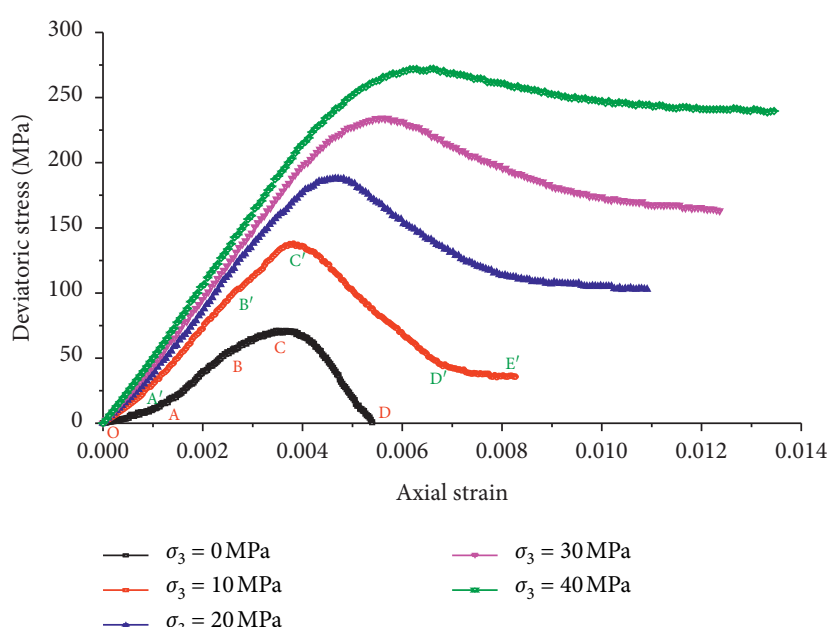

(b)

Figure 5: Compressive stress-strain curves under different confining pressure. (a) Natural state. (b) Saturated state.

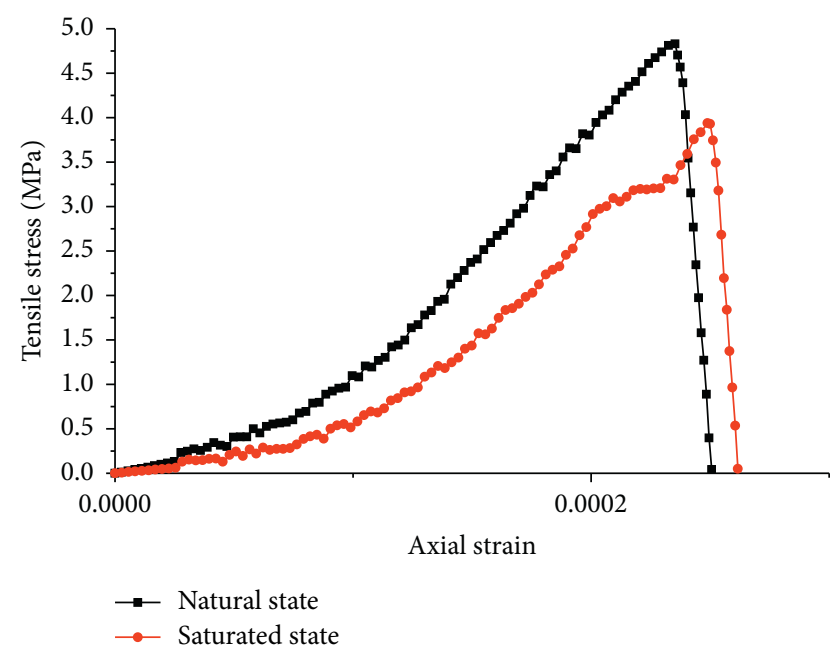

Figure 6: Tensile stress-strain curves for two water content states.

with the stress-strain curve obtained by the compression test, there is no obvious prepeak hardening and postpeak softening process on the tensile stress-strain curve.

For compression tests, deformation characteristics of rock are usually described by the elastic modulus, deformation modulus, and Poisson's ratio. According to CRTHWCE standards [36], the elastic modulus is defined as the slope of the straight line on the stress-strain curve before the peak strength. The deformation modulus, also known as the secant modulus, is defined as the ratio of stress to strain at half the peak strength of the stress-strain curve. Poisson's ratio is defined as the ratio of radial strain to axial strain. Similar to the definition of elastic modulus in the compression test, the tensile modulus for the direct tensile test can be determined as the slope of the straight line on the tensile stress-strain curve before the peak tensile stress. The definition of these deformation parameters can be written as follows:
(1) Elastic modulus : $E=\frac{\sigma_{b}-\sigma_{a}}{\varepsilon_{1 b}-\varepsilon_{1 a}}$,

(2) Deformation modulus : $\cdot E_{d}=\frac{\sigma_{50}}{\varepsilon_{l 50}}$,

$$
\text { (3) Poisson's ratio: } \mu=-\frac{\varepsilon_{3 b}-\varepsilon_{3 a}}{\varepsilon_{1 b}-\varepsilon_{1 a}} \text {, }
$$

$$
\text { (4) Tensile modulus : } \cdot E_{T}=\frac{\sigma_{T b}-\sigma_{T a}}{\varepsilon_{T b}-\varepsilon_{T a}} \text {, }
$$

where $\sigma_{a}$ and $\sigma_{b}$ are the stress values at the endpoints of the straight line on the stress-strain curve for the compression test; $\varepsilon_{1 a}$ and $\varepsilon_{1 b}$ are the axial strain values at the endpoints of the straight line on the stress-strain curve for the compression test; $\varepsilon_{3 a}$ and $\varepsilon_{3 b}$ are the lateral strain values at the endpoints of the straight line on the stress-strain curve for the compression test; $\sigma_{50}$ and $\varepsilon_{150}$ correspond to the stress and strain values at $50 \%$ of the peak strength on the stressstrain curve for the compression test; $\sigma_{T a}$ and $\sigma_{T b}$ are the stress values at the endpoints of the straight line on the tensile stress-strain curve for the direct tensile test; $\varepsilon_{T a}$ and $\varepsilon_{T b}$ are the strain values at the endpoints of the straight line on the tensile stress-strain curve for direct tensile test.

According to the stress-strain curves in Figures 5 and 6, the deformation parameters calculated by equations (2) (5) for two water content states are listed in Table 2. It can be seen that the elastic modulus, deformation modulus, and tensile modulus of Yunnan limestone decrease remarkably after saturation, only about $70 \%$ of the natural state on average. Therefore, the water can significantly enhance the deformation capacity of rocks and largely reduce the stiffness of Yunnan limestone. In order to quantitatively investigate the influence of confining pressure on elastic modulus and deformation modulus of rock, the evolution law of elastic modulus and deformation modulus versus confining pressure for two water content states is presented in Figure 7. 
TABle 2: Deformation parameters of Yunnan limestone under natural and saturated conditions.

\begin{tabular}{lcccccccc}
\hline \multirow{2}{*}{$\sigma_{3}(\mathrm{MPa})$} & \multicolumn{2}{c}{$E(\mathrm{GPa})$} & \multicolumn{2}{c}{$E_{d}(\mathrm{GPa})$} & \multicolumn{2}{c}{$\mu$} & \multicolumn{2}{c}{$E_{T}(\mathrm{GPa})$} \\
& Natural state & Saturated state & Natural state & Saturated state & Natural state & Saturated state & Natural state & Saturated state \\
\hline 0 & 40.3 & 35.4 & 21.6 & 16.6 & 0.28 & 0.28 & 30.1 & -23.5 \\
10 & 66.5 & 45.7 & 46.2 & 35.8 & 0.27 & 0.28 & - \\
20 & 76.6 & 51.3 & 58.9 & 43.5 & 0.29 & 0.29 & - & - \\
30 & 81.4 & 53.9 & 64.9 & 48.3 & 0.28 & 0.28 & - \\
40 & 84.3 & 55.7 & 68.1 & 51.3 & 0.29 & 0.28 & - \\
\hline
\end{tabular}

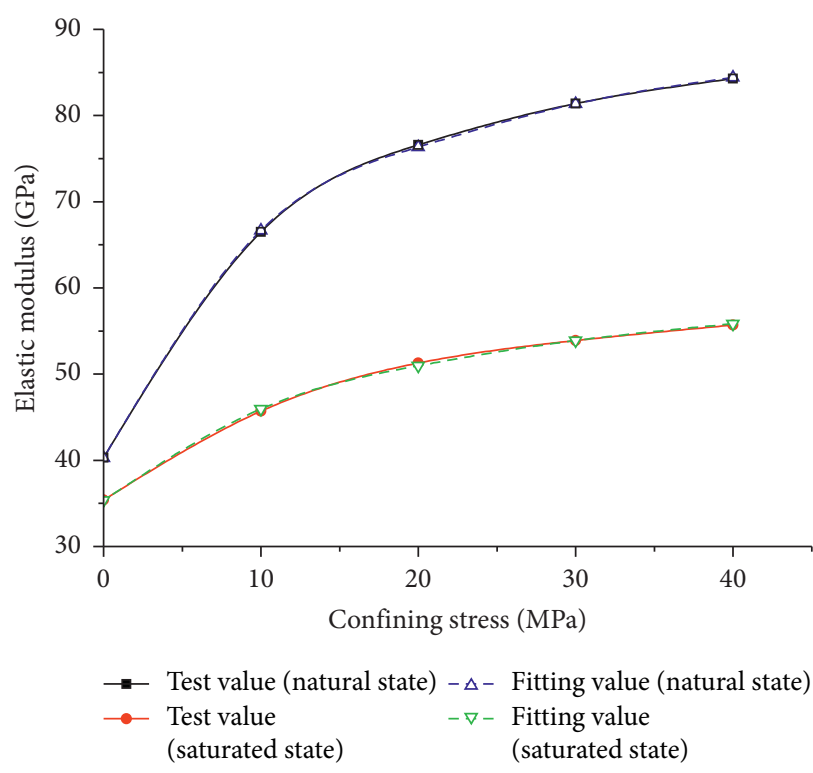

(a)

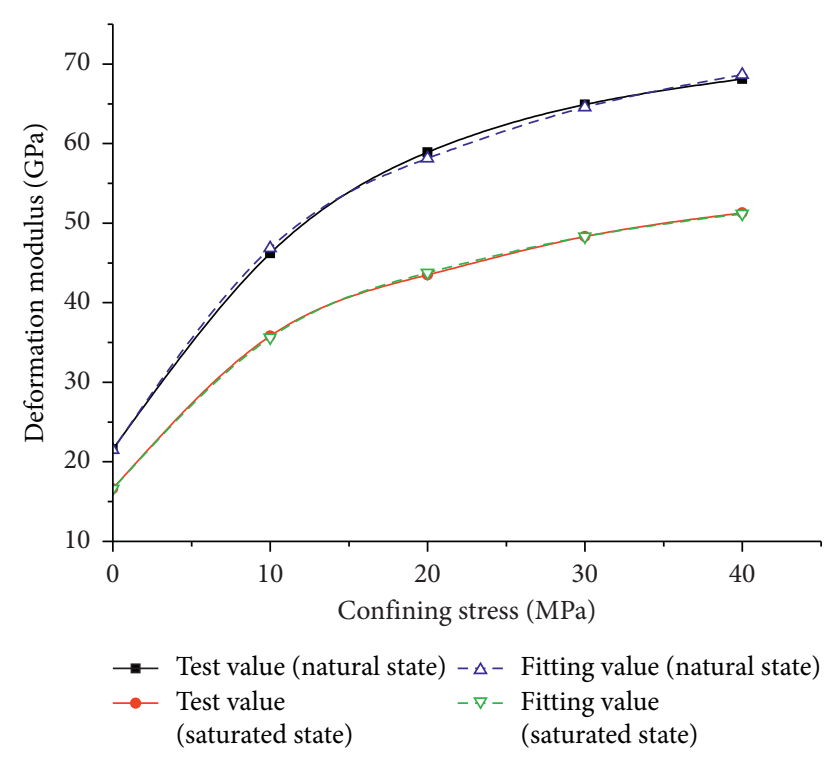

(b)

FiguRe 7: Relationships between elastic modulus, deformation modulus, and confining pressure for two water content states. (a) Elastic modulus versus confining pressure. (b) Deformation modulus versus confining pressure.

Clearly, the elastic modulus and deformation modulus have a distinct confining pressure effect. Under low confining pressure, the elastic modulus and deformation modulus increase rapidly. However, with the increase of confining pressure, the elastic modulus and deformation modulus tend to be stable and the confining pressure effect gradually weakens. In general, with the increase of confining pressure, the elastic modulus and deformation modulus of Yunnan limestone generally increase in the form of hyperbolic function.

Based on the MATLAB platform, the relationship between elastic modulus, deformation modulus, and confining pressure is fitted by the least square method. The corresponding fitted formulas are listed in Table 3, and the comparison between the fitted curves and the experimental values is shown in Figure 7. It shows that the fitting curves and the experimental values for the two water content states are in excellent agreement. Therefore, the qualitative relationship between deformation parameters of Yunnan limestone and confining pressure under natural and saturated conditions can be well represented by the fitted formulas. As for the Poisson's ratio, regardless of the increasing confining pressure or the change of water content, it changes very little and remains basically a constant, about 0.28 . Thus, it can be concluded that confining pressure and water content have little effect on Poisson's ratio of Yunnan limestone.

3.3. Strength Characteristics. Through the above analysis, the stress-strain curves (Figure 5) obtained from conventional triaxial compression can be simplified into three straight lines, as shown in Figure 8. These straight lines represent the linear elastic stress stage, the postpeak plastic softening stage, and the residual stress stage, respectively. Figure 5 shows that the confining pressure has a significant effect on the slope of the straight line in the postpeak plastic softening stage. That is, the slope of the straight line in the plastic softening stage decreases gradually with the increase of confining pressure. To this end, previous researchers $[37,38]$ define the slope of the postpeak plastic softening stage as the softening modulus, and its expression is as follows:

$$
M=\left|\frac{\sigma_{p}-\sigma_{r}}{\varepsilon_{p}-\varepsilon_{r}}\right|,
$$

where $\sigma_{p}$ denotes the peak strength; $\sigma_{r}$ denotes the residual strength; $M$ denotes the softening modulus; $\varepsilon_{p}$ denotes the peak strain; $\varepsilon_{r}$ denotes the critical strain from the plastic 
TABLE 3: Fitted formulas for elastic modulus and deformation modulus of Yunnan limestone under natural and saturated conditions.

\begin{tabular}{lcccc}
\hline $\begin{array}{l}\text { Deformation } \\
\text { parameters }\end{array}$ & Natural condition & $\begin{array}{c}\text { Correlation } \\
\text { coefficient }\end{array}$ & Saturated condition & $\begin{array}{c}\text { Correlation } \\
\text { coefficient }\end{array}$ \\
\hline$E$ & $\left(70.18 \sigma_{3} / 1.23 \sigma_{3}-14.3\right)+40.3$ & 0.99 & $\left(170.65 \sigma_{3} / 5.74 \sigma_{3}-103.91\right)+35.36$ & 0.99 \\
$E_{d}$ & $\left(777.64 \sigma_{3} / 11.75 \sigma_{3}-189.38\right)+21.5$ & 0.99 & $\left(381.98 \sigma_{3} / 8.03 \sigma_{3}-120.82\right)+16.62$ & 0.99 \\
\hline
\end{tabular}

Note. $\sigma_{3}$ represents the magnitude of confining pressure.

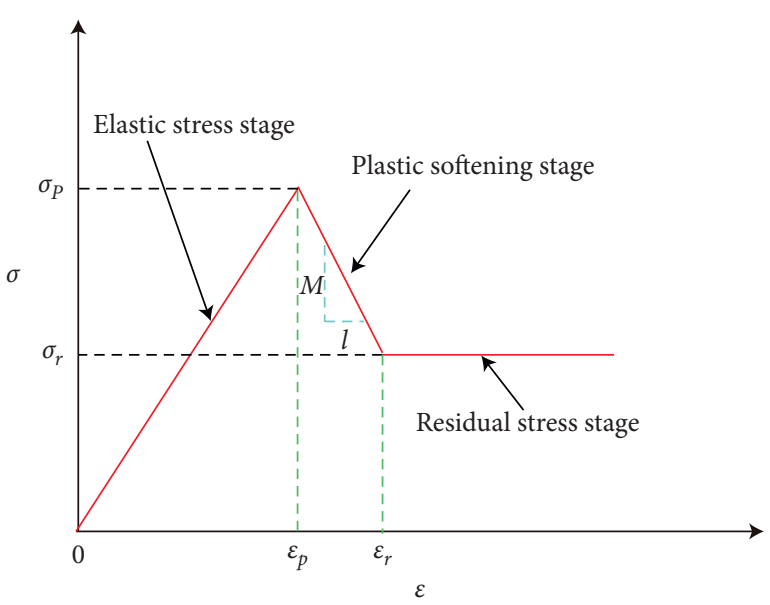

FIGURE 8: Simplified stress-strain curve for a conventional triaxial compression test. $\sigma_{p}$ denotes the peak strength. $\sigma_{r}$ denotes the residual strength. $\mathrm{M}$ denotes the softening modulus. $\varepsilon_{p}$ denotes the peak strain. $\varepsilon_{r}$ denotes the residual strain.

softening stage to the residual stress stage. Their specific meanings can be seen in Figure 8.

Table 4 lists the strength parameters for Yunnan limestone from the conventional triaxial compression tests and direct tensile tests, including peak strength, residual strength, softening modulus, and tensile strength. Clearly, the peak strength and residual strength of Yunnan limestone increase significantly with the increasing confining pressure, whereas the softening modulus is the opposite for both natural and saturated states. In addition, the peak strength, residual strength, softening modulus, and tensile strength of Yunnan limestone have been reduced to some extent after saturation. Specifically, the peak strength, residual strength, softening modulus, and tensile strength of the rock in the saturated state are only $87 \%, 83 \%, 78 \%$, and $81 \%$ of those in the natural state. So, the water content can not only degrade the stiffness of Yunnan limestone but also significantly deteriorate its strength.

In order to quantitatively study the influence of confining pressure on strength parameters of Yunnan limestone for the natural and saturated state, the evolution of peak strength, residual strength, and softening modulus versus confining pressure for two water content states are presented in Figure 9.

From Figure 9, the peak strength and softening modulus of Yunnan limestone possess a distinctly nonlinear characteristic with the increase of confining pressure. In addition, the larger the confining pressure, the smaller the variation amplitude of peak strength and softening modulus. Overall, their evolutionary trends are in line with the law of quadratic polynomial function. However, the residual strength increases linearly with the increase of confining pressure. Based on the least square principle, the strength parameters of Yunnan limestone under different confining pressures for two water content states can be determined by the regression analysis method. The corresponding fitted formulas are listed in Table 5, and a comparison between the fitted curves and experimental values is shown in Figure 9. It can be seen that the fitted curves are very close to the experimental values, and all the correlation coefficients are over 95\%. Therefore, the fitted formulas can well describe the quantitative relationships between strength parameters of Yunnan limestone and confining pressure for the natural and saturated state.

\section{Discussion}

4.1. Failure Mode and Failure Mechanism. In previous publications, researchers considered that water content has a great influence on the rock failure mode. Through the uniaxial compression test, Liu et al. [39] found that the failure mode was mainly tensile failure when the sample was partly wetted with water, but shear failure dominated for the specimens that were fully saturated with water. However, by comparing the failure modes between natural specimens and saturated specimens in our research, we found that the failure mode of rock in the natural state and saturated state is basically consistent under the same confining pressure. It indicated that the water content has little effect on the failure mode of Yunnan limestone. In Liu's research, the rock specimens used for the experiment are the sandstone retrieved from the coal roof of the Xiaojihan mine. According to the petrographic study of thin sections, the sandstone mainly consists of quartz (40-50\%), feldspar (10-20\%), and minor amounts of mica, with greater than $8 \%$ clay content by weight. As is known to all, the clay mineral is sensitive to water. In addition, the diagenesis of the sandstones is weak, with porous cementation to contact cementation during diagenesis. In our study, Yunnan limestone is a kind of compact rock with low porosity $(1.32 \%)$, and its mineral components contain a large amount of calcite (more than $96 \%$ ) and a small amount of quartz (less than $4 \%$ ). Therefore, we infer that the mineral composition and internal structure may lead to the differences in rock failure modes under different water contents. As the failure modes of Yunnan limestone under two water content conditions are basically the same, we will take the failure mode of Yunnan limestone in the natural state as an example for discussion in the following text.

Figure 10 presents the failure modes of Yunnan limestone specimens from the conventional triaxial compression 
TABLE 4: Strength parameters of Yunnan limestone under natural and saturated conditions.

\begin{tabular}{|c|c|c|c|c|c|c|c|c|}
\hline \multirow{2}{*}{$\sigma_{3}(\mathrm{MPa})$} & \multicolumn{2}{|c|}{$\sigma_{P}(\mathrm{MPa})$} & \multicolumn{2}{|c|}{$\sigma_{r}(\mathrm{MPa})$} & \multicolumn{2}{|c|}{$M(\mathrm{GPa})$} & \multicolumn{2}{|c|}{$\sigma_{t}(\mathrm{MPa})$} \\
\hline & Natural state & Saturated state & Natural state & Saturated state & Natural state & Saturated state & Natural state & Saturated state \\
\hline 0 & 79.1 & 69.5 & 0 & 0 & 67.1 & 58.9 & 4.8 & 3.9 \\
\hline 10 & 151.7 & 135.8 & 50.1 & 34.9 & 40.9 & 30.1 & - & - \\
\hline 20 & 220.3 & 186.9 & 116.9 & 102.0 & 22.4 & 17.9 & - & - \\
\hline 30 & 267.1 & 232.4 & 193.2 & 162.4 & 14.6 & 11.3 & - & - \\
\hline 40 & 307.9 & 270.6 & 265.7 & 237.7 & 9.6 & 7.0 & - & - \\
\hline
\end{tabular}

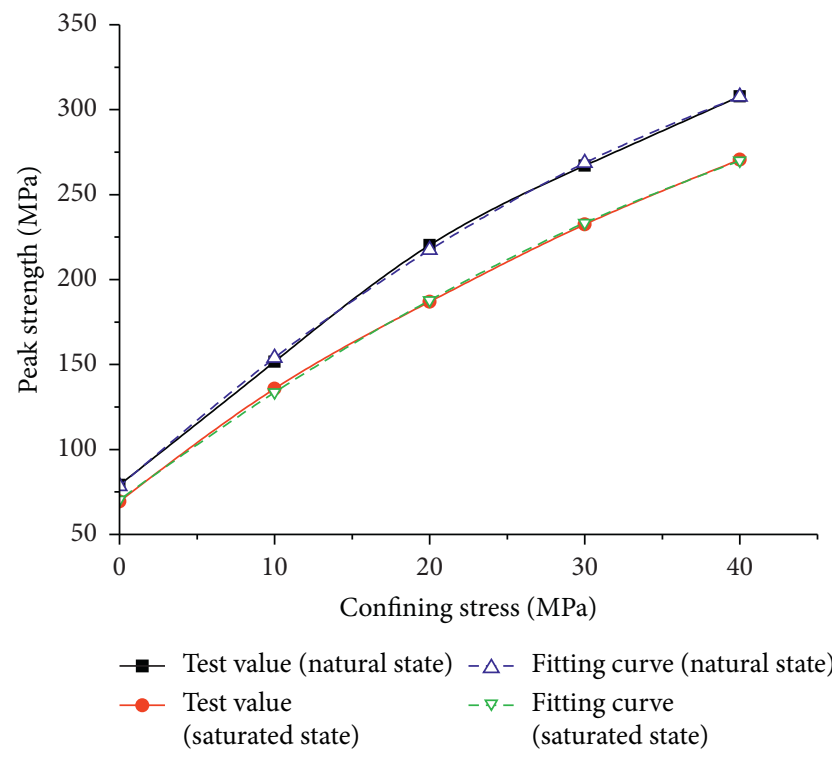

(a)

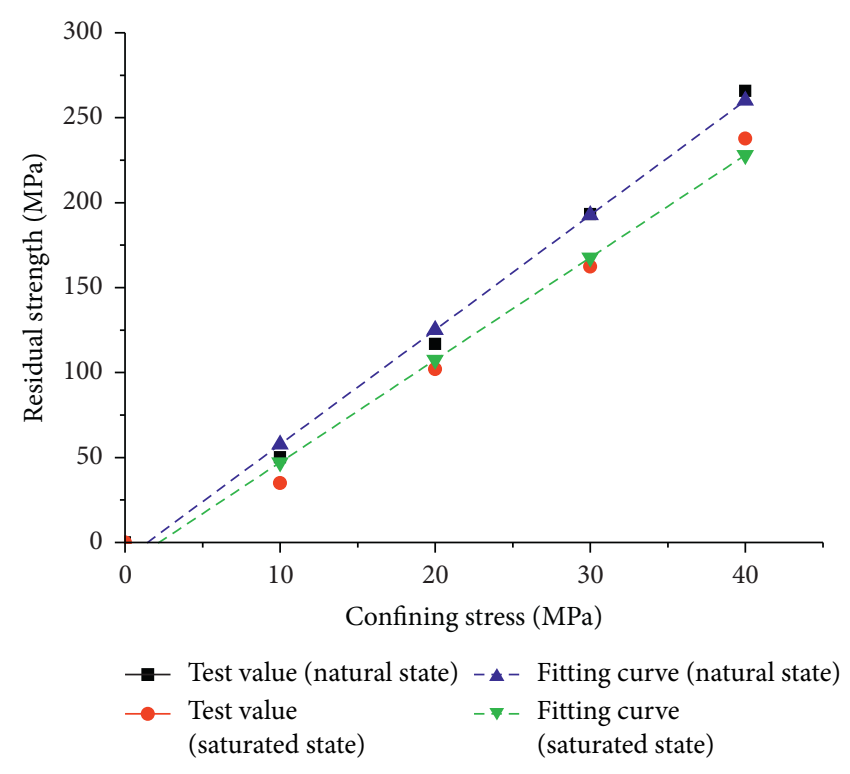

(b)

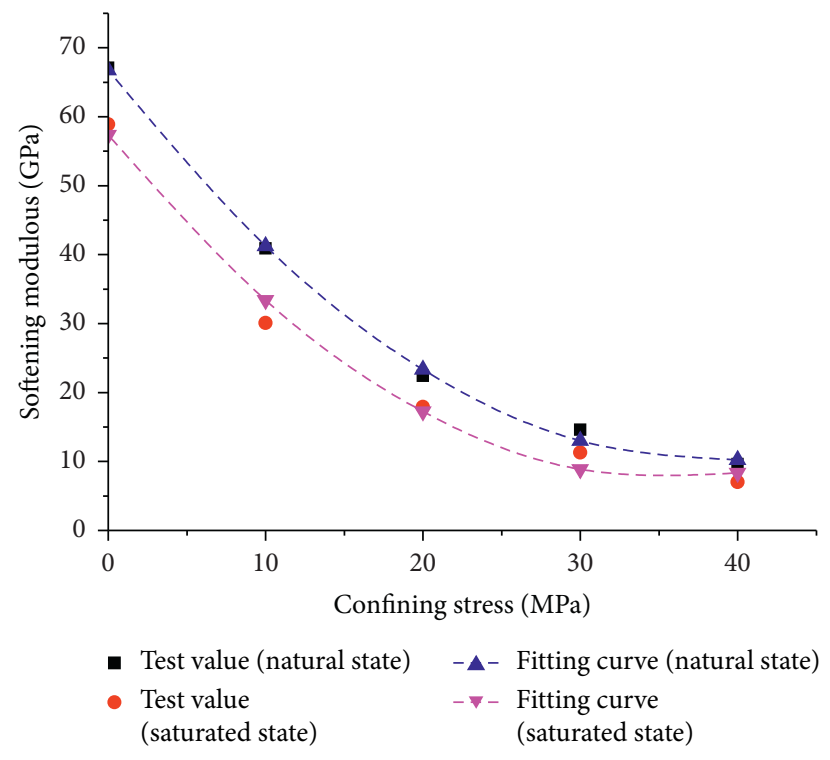

(c)

FIGURE 9: Relationships between peak strength, residual strength, softening modulus, and confining pressure for two water content states. (a) Peak strength versus confining pressure. (b) Residual strength versus confining pressure. (c) Softening modulus versus confining pressure. 
TABLE 5: Fitted formulas for peak strength, residual strength, and softening modulus of Yunnan limestone under natural and saturated conditions.

\begin{tabular}{lcccc}
\hline Strength parameters & Natural condition & Correlation coefficient & Saturated condition & Correlation coefficient \\
\hline$\sigma_{P}$ & $0.06 \sigma_{3}^{2}+8.17 \sigma_{3}+78.42$ & 0.99 & $0.044 \sigma_{3}^{2}+6.75 \sigma_{3}+70.45$ & 0.99 \\
$\sigma_{r}$ & $6.75 \sigma_{3}-9.72$ & 0.96 & $6.03 \sigma_{3}-13.18$ & 0.95 \\
$M$ & $0.038 \sigma_{3}^{2}-2.93 \sigma_{3}+66.77$ & 0.99 & $0.039 \sigma_{3}^{2}-2.79 \sigma_{3}+57.36$ & 0.99 \\
\hline
\end{tabular}

Note: $\sigma_{3}$ represents the magnitude of confining pressure.

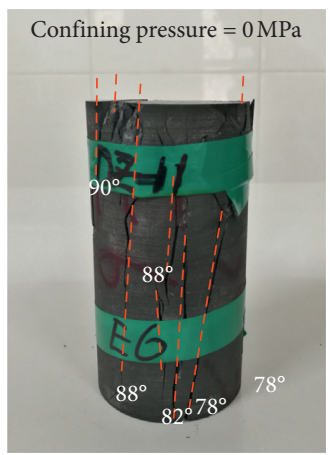

(a)

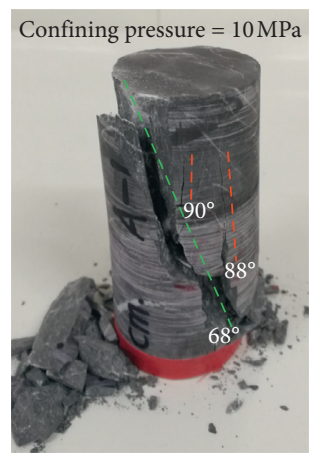

(b)

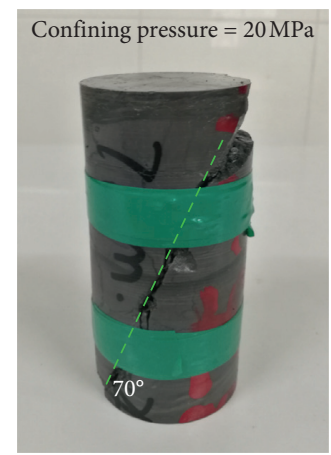

(c)

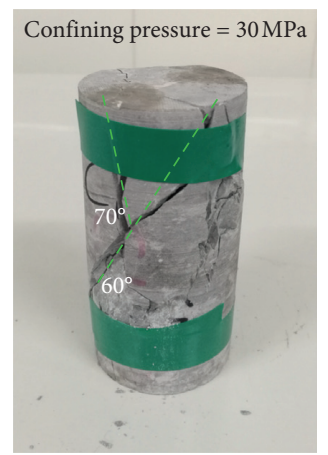

(d)

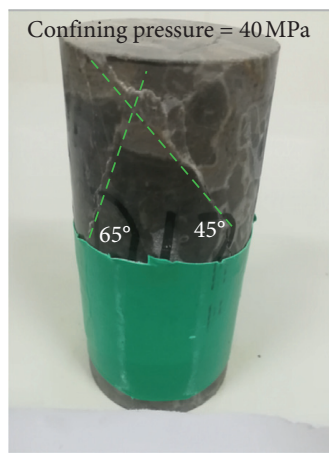

(e)

FIGURE 10: Failure modes of Yunnan limestone under different confining pressures. (a) Splitting failure. (b) Tension-shear mixed failure. (c) Single inclined surface shear failure. (d) Y-shaped shear failure. (e) X-shaped shear failure. The dashed line in red represents the tensile crack. The dashed line in green represents the shear crack.

tests. In the figure, the emerged cracks are marked with the dashed lines.

From Figure 10, it can be clearly seen that under different confining pressures, Yunnan limestone specimens manifest different failure patterns. Under uniaxial compression, the axial cracks extend to the end surface and split the specimen into columns. These cracks tend to be steep, most of which are inclined from $80^{\circ}$ to $90^{\circ}$. At confining pressure of $10 \mathrm{MPa}$, the specimen showed a shear mode failure with local tensile cracks. Along with the specimen, a typical shear band with an inclination of about $70^{\circ}$ is formed from the upper left to the lower right, and a lot of rock debris is generated. In the meantime, some splitting cracks with an inclination of about $90^{\circ}$ in the local position of the specimen are also observed. At confining pressure of $20 \mathrm{MPa}$, the specimen failed by the typical single inclined plane shear failure mode with a diagonal fracture, and the inclination of the fracture is about $70^{\circ}$. The fracture surface is found to be smooth and flat, which is the result of frictional sliding of the macroscopic fracture surfaces. At confining pressure of $30 \mathrm{MPa}$, the specimen exhibits $\mathrm{Y}$-shaped shear failure, and there is almost no tensile crack. Under higher confining pressures of $40 \mathrm{MPa}$, two closed X-shaped conjugated shear cracks are observed in the specimen. Due to the restraint effect of high confining pressure, no through cracks are formed in the specimen. Overall, with the increase of confining pressure, the failure modes of Yunnan limestone specimens vary from splitting failure to tension-shear mixed failure, to single inclined plane shear failure, and to $\mathrm{Y}$-shaped or X-shaped conjugated shear failure.

Figure 11 depicts the failure mode of the Yunnan limestone specimen from the direct tensile test. It can be seen that when the specimen reaches the tensile strength, the specimen is pulled out into two parts along the relatively weak section. In general, the failure surface of the specimens is relatively flat and smooth, although there are some microcleavages caused by local initial defects.

In order to study the failure mechanism of Yunnan limestone under different stress conditions, the rock slice taken from the fracture surface was scanned by the electron microscope scanning system. The utilized electron microscope scanning system in the present study is the Thermo Scientific ${ }^{\mathrm{TM}}$ Quattro scanner made in the USA, which is shown in Figure 12(a). Figure 12(b) presents the rock slices of Yunnan limestone to be scanned, which are taken from the fracture surface of the specimen. Figure 12(c) presents the scanning of the internal structure of the specimen in its initial state. It can be seen that Yunnan limestone is a typical heterogeneous material, which has been initially damaged in the long geological history. There are microdefects such as fissures and holes at different scales in the specimens, which lead to a longer initial crack closure stage of the uniaxial compression stress-strain curve. Figures 12(d)-12(f) present the SEM photomicrograph of fracture surface from direct tensile test and low confining pressure tests $\left(\sigma_{3} \leq 10 \mathrm{MPa}\right)$. Clearly, the fracture surface is relatively clean and there is no significant scratch of friction and slip, indicating that the failure is mainly caused by stretching or splitting. Figures $12(\mathrm{~g})-$ 12(i) show the SEM photomicrograph of fracture surface under high confining pressure $\left(\sigma_{3} \geq 20 \mathrm{MPa}\right)$. It can be seen that there are some scratches on the fracture surface, which are distributed in steps and scales along the shear slip direction (the direction of the red arrow in the figures). 


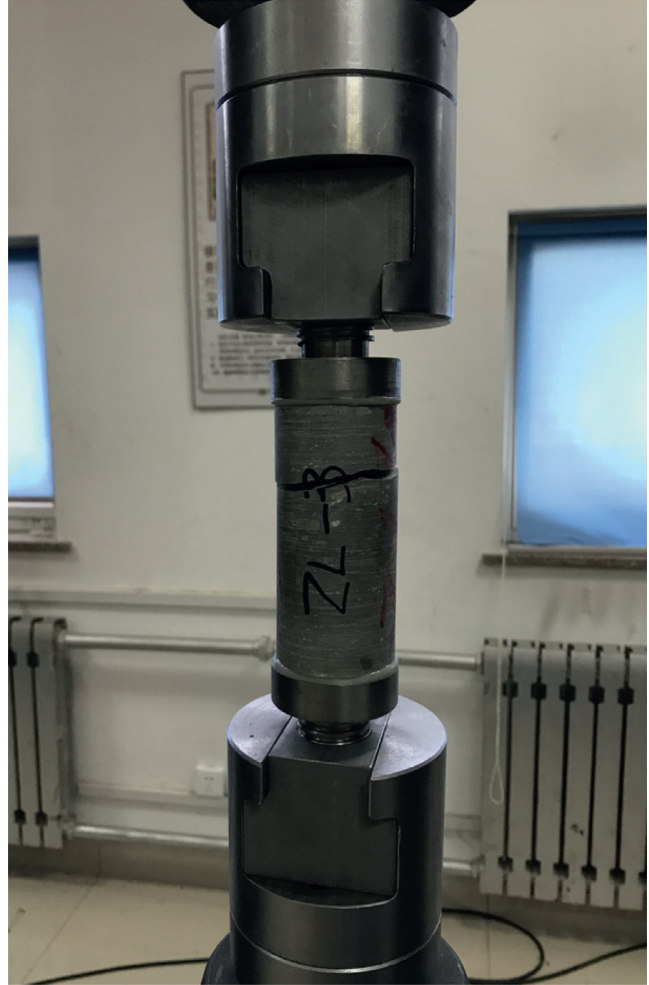

(a)

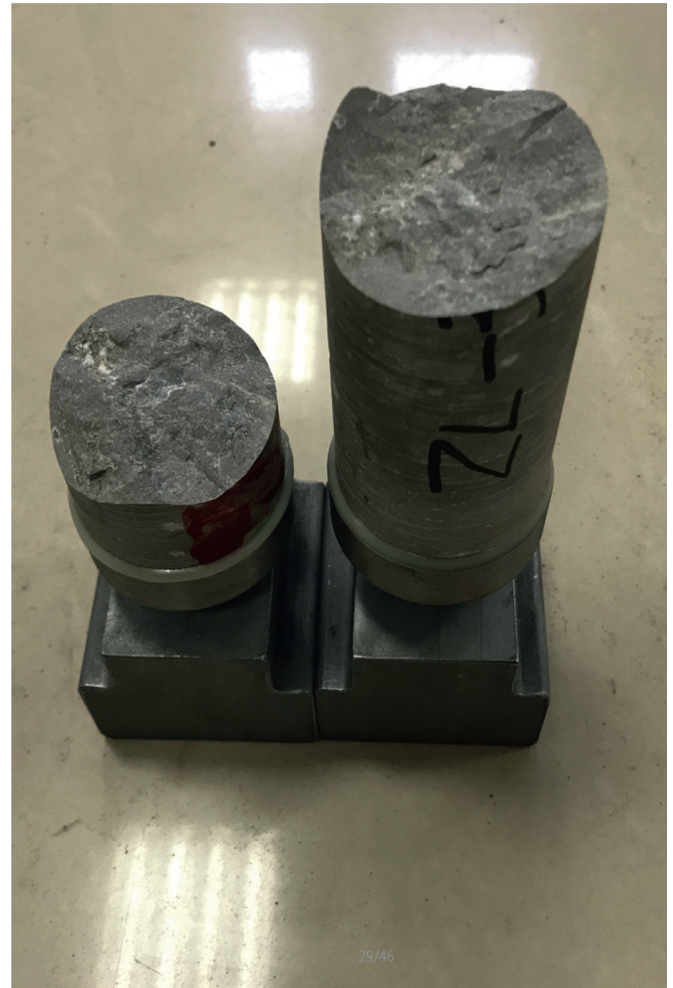

(b)

Figure 11: Failure modes of Yunnan limestone in the direct tensile test.

Therefore, the failure of Yunnan limestone under high confining pressure is mainly caused by a shear slip of crack surface.

\subsection{Applicability of Hoek-Brown Strength Criterion. A large} number of experimental studies have demonstrated that with the increase of confining pressure, the maximum principal stress and the minimum principal stress no longer meet the linear Mohr-Coulomb criterion. That is, the strength envelope of rock displays a significant nonlinear trend [28-31]. Consistent conclusions were also obtained from the above-mentioned strength analysis of Yunnan limestone. The Hoek-Brown criterion is a typical nonlinear strength criterion, which has been widely used in geotechnical engineering. Next, the applicability of the HoekBrown strength criterion for natural and saturated Yunnan limestone will be discussed.

Through the statistical analysis of a large number of laboratory and field test results, Hoek and Brown [40] proposed an empirical strength criterion, i.e., the HoekBrown criterion. Subsequently, Hoek [41] revised the previous version and established the generalized Hoek-Brown criterion, which can be written as follows:

$$
\begin{aligned}
& \sigma_{1}=\sigma_{3}+\sigma_{c}\left(m_{b} \frac{\sigma_{3}}{\sigma_{c}}+s\right)^{a}, \\
& m_{b}=m_{i} \exp \left(\frac{\mathrm{GSI}-100}{28-14 D}\right),
\end{aligned}
$$

$$
\begin{aligned}
& s=\exp \left(\frac{\mathrm{GSI}-100}{9-3 D}\right), \\
& a=0.5+\frac{1}{6}\left[\exp \left(\frac{\mathrm{GSI}}{15}\right)-\exp \left(\frac{20}{3}\right)\right],
\end{aligned}
$$

where $\sigma_{1}$ and $\sigma_{3}$ denote the maximum principal stress and minimum principal stress (confining pressure); $\sigma_{c}$ denotes uniaxial compressive strength of intact rock; $m_{i}, m_{b}, s$, and a denote empirical coefficients. GSI (geological strength index) is an indicator of rock quality, which ranges from 0 to 100. $D$ is a factor that depends upon the degree of disturbance to which the rock mass has been subjected by blast damage and stress relaxation. It varies from 0 for undisturbed in situ rock masses to 1 for very disturbed rock masses. $m_{i}$ reflects the hardness of rock. Its range is from 0 for seriously disturbed rock mass to 25 for intact hard rock mass. According to equations (8) (10), the range of $m_{b}$ is $0 \sim 25$, that of $s$ is $0 \sim 1$, and that of a is $0.5 \sim 0.67$. It should be noted that the compressive stress is positive and the tensile stress is negative in this paper.

Based on the generalized Hoek-Brown criterion, we fit the peak and residual strength envelopes of Yunnan limestone under natural and saturated conditions by the least square method. The fitted Hoek-Brown strength parameters are listed in Table 6. Figure 13 shows the comparison between the fitted strength envelopes and the strength envelopes obtained from the test. Here, the peak maximum 


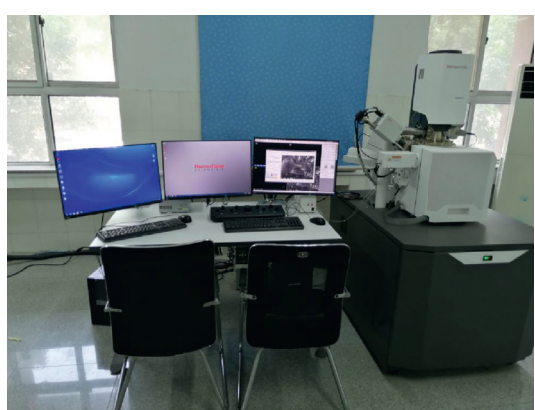

(a)

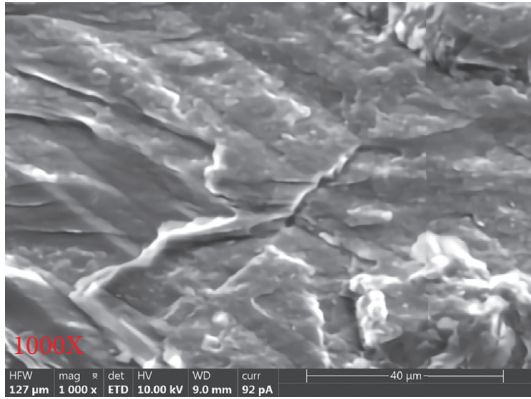

(d)

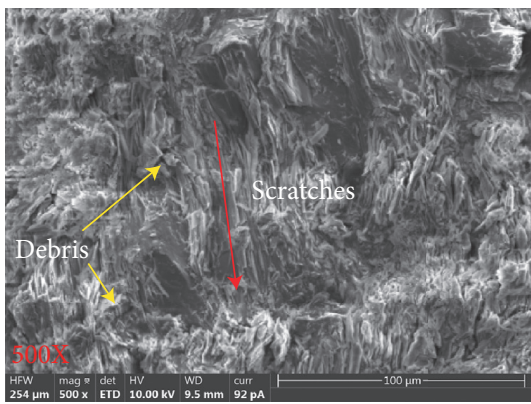

(g)

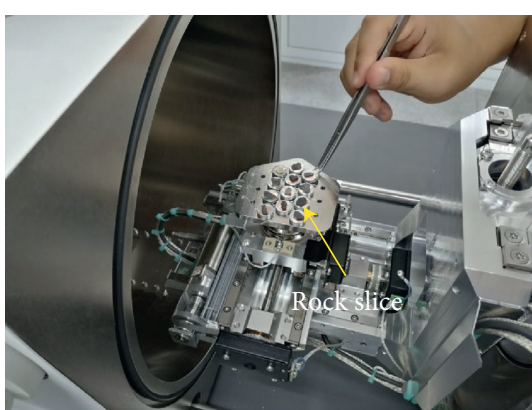

(b)

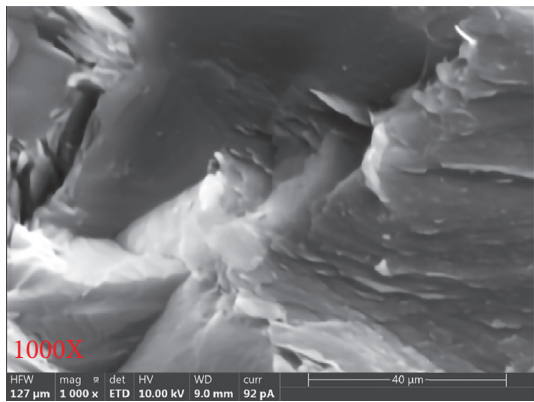

(e)

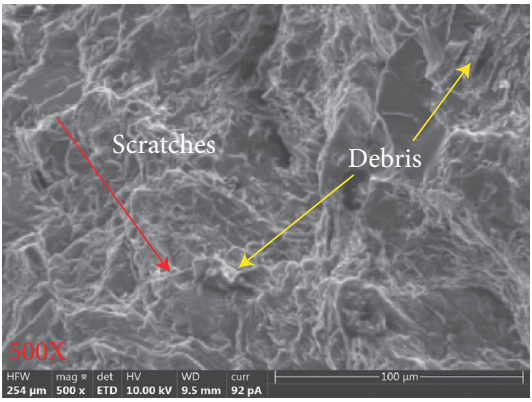

(h)

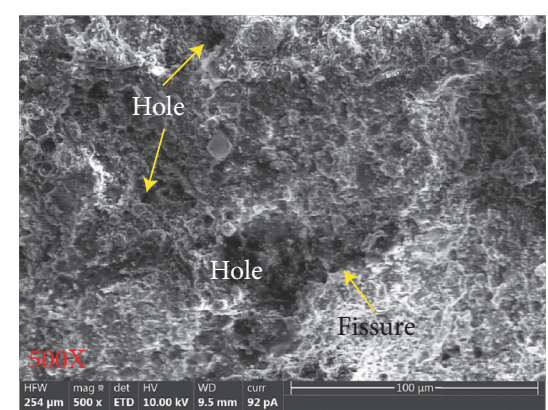

(c)

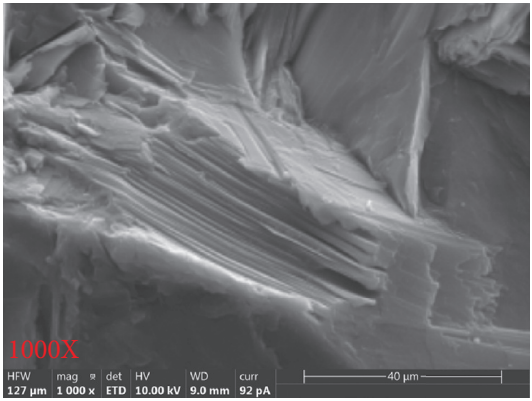

(f)

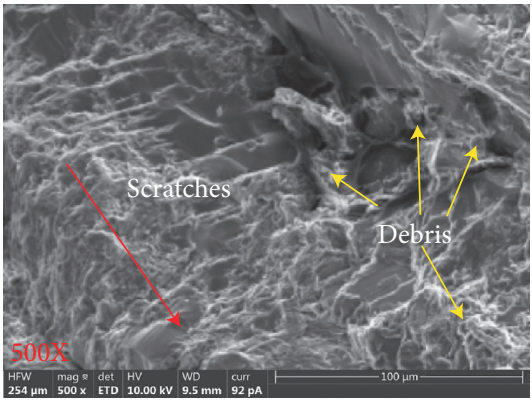

(i)

FIGURE 12: SEM photomicrograph of Yunnan limestone fracture surface for different test cases. (a) Electron microscope scanning system. (b) Rock slice on the fracture surface. (c) Internal structure in the initial state. (d) Direct tensile test. (e) Uniaxial compression test (confining pressure $=0 \mathrm{MPa}$ ). (f) Triaxial compression test (confining pressure $=10 \mathrm{MPa})$. (g) Triaxial compression test $($ confining pressure $=20 \mathrm{MPa})$. (h) Triaxial compression test (confining pressure $=30 \mathrm{MPa}$ ). (i) Triaxial compression test (confining pressure $=40 \mathrm{MPa}$ ).

TABLE 6: Fitted strength parameters of the Yunnan limestone based on the generalized H-B strength criterion.

\begin{tabular}{|c|c|c|c|c|}
\hline Parameter type & Water content state & $M_{b}$ & $s$ & $a$ \\
\hline \multirow{2}{*}{ Peak strength parameter } & Natural & 16.38 & 0.98 & 0.61 \\
\hline & Saturated & 13.05 & 0.97 & 0.64 \\
\hline Residual strength parameter & $\begin{array}{c}\text { Natural } \\
\text { Saturated }\end{array}$ & $\begin{array}{l}4.82 \\
3.97\end{array}$ & $\begin{array}{l}-0.03 \\
-0.06\end{array}$ & $\begin{array}{l}1.20 \\
1.31\end{array}$ \\
\hline
\end{tabular}

principal stress $\sigma_{1 p}$ and residual maximum principal stress $\sigma_{1 r}$ at confining pressure $\sigma_{3}$ can be written as follows:

$$
\begin{gathered}
\sigma_{1 p}=\sigma_{p}+\sigma_{3}, \\
\sigma_{1 r}=\sigma_{r}+\sigma_{3},
\end{gathered}
$$

where the meanings of $\sigma_{p}$ and $\sigma_{r}$ are the same as in equation (8).

It can be seen that the fitted curves are in good agreement with the test results. However, it is not enough to judge the applicability of the generalized Hoek-Brown strength criterion to the strength of Yunnan limestone only from the point of fitting error, and the rationality of the corresponding strength parameters must be considered. For the peak strength envelopes, the strength parameters $m_{b}, s$, and $a$ of the Yunnan limestone in the natural state and saturated state are $16.38,0.98,0.61$, and $13.05,0.97,0.64$, respectively, which are all in a reasonable range. Moreover, due to the influence of water content, the strength parameters $m_{b}$ and $s$ decrease, while a increases, indicating that the strength of 


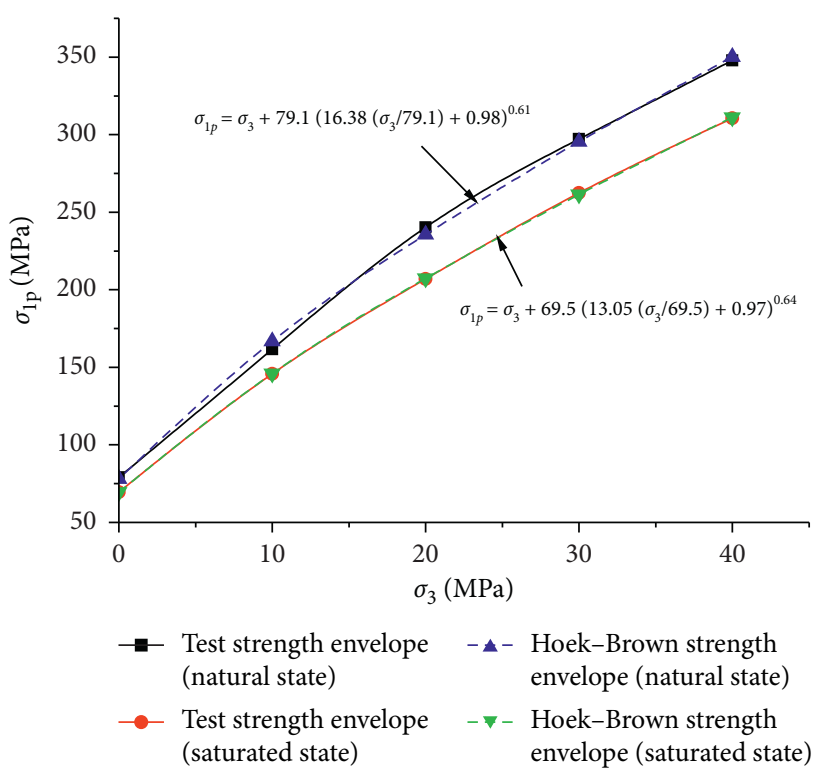

(a)

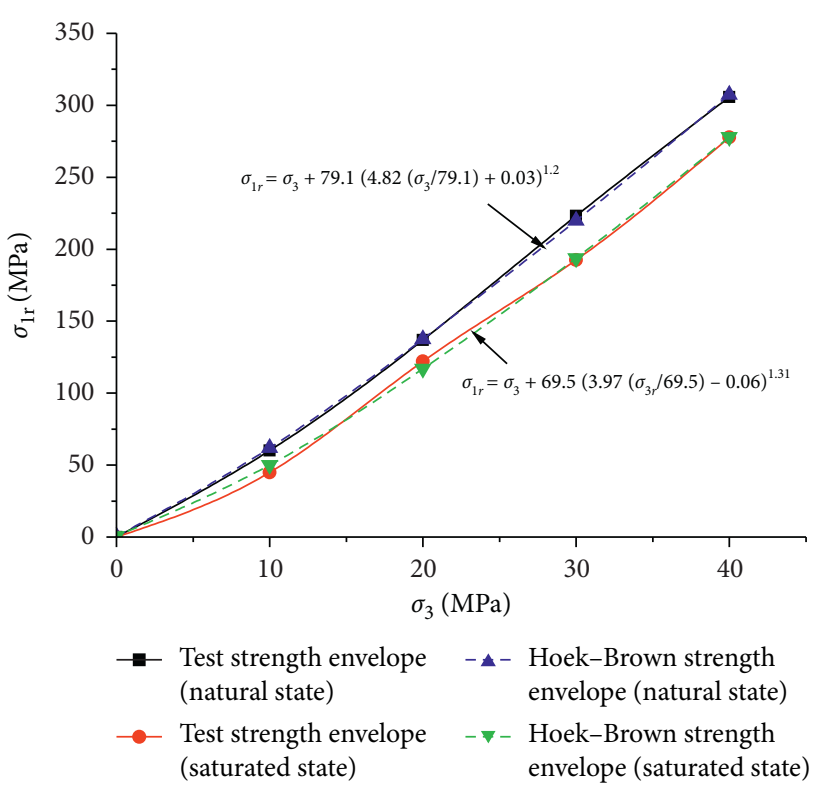

(b)

Figure 13: Strength envelopes of Yunnan limestone. (a) Peak strength envelope. (b) Residual strength envelope. $\sigma_{1 p}$ and $\sigma_{1 r}$ represent the peak and residual maximum principal stress at confining pressure $\sigma_{3}$, respectively.

Yunnan limestone decreases after water saturation, which is consistent with the analysis of the above test results. However, for the residual strength, except for the parameter $m_{b}$, both $s$ $(s<0)$ and a $(a>0.67)$ are outside of the corresponding range. Therefore, we can conclude that the Hoek-Brown strength criterion does not apply to the residual strength of Yunnan limestone. This conclusion has also been confirmed in the publication of other researchers [42-44]. Through careful analysis of these relevant works of literature, it is found that the rocks whose residual strength envelope does not meet the Hoek-Brown strength criterion have distinct brittle-ductile transition trends. In fact, as early as the establishment of the Hoek-Brown criterion, Hoek and Brown [40] pointed out that the criterion is only applicable to brittle fracture of rock, not to ductile failure. Therefore, the Hoek-Brown criterion does not apply to residual strength with ductile failure [45]. Also, according to the aforementioned failure mode of Yunnan limestone, a macroscopic fracture surface was formed inside the sample at the residual stress stage. The residual strength is only provided by the friction angle on the fracture surface, so the residual strength envelope is a straight line that approximately passes through the origin (see Figure 9(b)). Quite evidently, the nonlinear Hoek-Brown criterion does not hold.

\section{Conclusions}

With Xianglu Mountain Tunnel of Yunnan Water Diversion Project in China as the engineering background, a series of conventional triaxial compression tests and direct tensile tests were conducted to investigate the mechanical behavior of Yunnan limestone under natural and saturated conditions. Based on the analysis of the test results, some conclusions can be drawn:
(1) Water content can not only degrade the stiffness of Yunnan limestone, but also deteriorate its strength. The deformation modulus, tensile modulus, peak strength, residual strength, and tensile strength of Yunnan limestone in the saturated state are only $70 \%, 70 \%, 87 \%$, $83 \%$, and $81 \%$ of those in the natural state on average.

(2) As confining pressure increases, the elastic modulus, deformation modulus, peak strength, and softening modulus of Yunnan limestone present a nonlinear law, while the residual strength possesses a linearly increasing trend. Employing the regression analysis method, quantitative relationships between elastic modulus, deformation modulus, peak strength, residual strength and softening modulus, and confining pressure were established for nature and saturated Yunnan limestone.

(3) With the increasing confining pressure, the failure modes of Yunnan limestone transform from axial splitting failure, tension-shear mixed failure, single inclined plane shear failure to conjugated inclined plane shear failure. In addition, the widely used generalized Hoek-Brown strength criterion can well describe the peak strength envelope of Yunnan limestone, but it is not applicable to the residual strength.

(4) The test results can provide an important data set for the establishment of the constitutive model of Yunnan limestone, which will contribute to obtain more convincing results for stability evaluation and engineering design of Xianglu Mountain Tunnel.

\section{Data Availability}

The data used to support the findings of this study are included within the article. 


\section{Conflicts of Interest}

The authors declare that there are no conflicts of interest regarding the publication of this paper.

\section{Acknowledgments}

This study was financially supported by the Research Fund of Liaocheng University (No. 318051616).

\section{References}

[1] B. Y. Bejarbaneh, E. Y. Bejarbaneh, M. F. M. Amin, A. Fahimifar, D. Jahed Armaghani, and M. Z. A. Majid, "Intelligent modelling of sandstone deformation behaviour using fuzzy logic and neural network systems," Bulletin of Engineering Geology and the Environment, vol. 77, no. 1, pp. 345-361, 2018.

[2] Q. C. Fang, B. Y. Bejarbaneh, M. Vatandoust, D. J. Armaghani, B. R. Murlidhar, and E. T. Mohamad, "Strength evaluation of granite block samples with different predictive models," Engineering with Computers, vol. 11, 2019.

[3] A. Mahdiyar, D. J. Armaghani, A. Marto, M. Nilashi, and S. Ismail, "Rock tensile strength prediction using empirical and soft computing approaches," Bulletin of Engineering Geology and the Environment, vol. 78, no. 6, pp. 4519-4531, 2018.

[4] Z. Shao, D. Jahed Armaghani, B. Yazdani Bejarbaneh, M. A. Mu'azu, and E. Tonnizam Mohamad, "Estimating the friction angle of black shale core specimens with hybrid-ANN approaches," Measurement, vol. 145, pp. 744-755, 2019.

[5] H. F. Deng, X. F. Yuan, J. L. Li, M. He, Q. Luo, and M. Zhu, "Experimental research on influence of saturation degree on sandstone longitudinal wave velocity and strength," Chinese Journal of Rock Mechanics and Engineering, vol. 32, no. 8, pp. 1625-1631, 2013.

[6] E. Kim and H. Changani, "Effect of water saturation and loading rate on the mechanical properties of Red and Buff Sandstones," International Journal of Rock Mechanics and Mining Sciences, vol. 88, pp. 23-28, 2016.

[7] W. Si, B. Di, J. Wei, and Q. Li, "Experimental study of water saturation effect on acoustic velocity of sandstones," Journal of Natural Gas Science and Engineering, vol. 33, pp. 37-43, 2016.

[8] B. Vásárhelyi and P. Ván, "Influence of water content on the strength of rock," Engineering Geology, vol. 84, no. 1-2, pp. 70-74, 2006.

[9] H. H. Zhu, Z. G. Zhou, and T. Deng, "Acoustic parameters of low-porosity rock under dry and saturated conditions," Chinese Journal of Rock Mechanics and Engineering, vol. 24, no. 5, pp. 823-828, 2005.

[10] C. Y. Zhou, Y. M. Deng, X. S. Tan, Z. Q. Liu, W. Shang, and S. Zhan, "Experimental research on the softening of mechanical properties of saturated soft rocks and application," Chinese Journal of Rock Mechanics and Engineering, vol. 24, no. 1, pp. 33-38, 2005.

[11] G. L. Chen and R. D. Zhou, "An experimental study concerning the macro-scopic effect of water on the deformation and failure of loaded rocks," Acta Geophysica Sinica, vol. 34, no. 3, pp. 335-342, 1991.

[12] A. B. Hawkins and B. J. Mcconnell, "Sensitivity of sandstone strength and deformability to changes in moisture content," Quarterly Journal of Engineering Geology and Hydrogeology, vol. 25, no. 2, pp. 115-130, 1992.
[13] J. Wang, M. He, and Z. W. Wang, "Relationship between the shear strength and water content of swelling sandstones," China Civil Engineering Journal, vol. 39, no. 1, pp. 98-102, 2006.

[14] D. G. Xiong, Z. P. Zhao, C. D. Su, and G. Y. Wang, "Experimental study of effect of water-saturated state on mechanical properties of rock in coal measure strata," Chinese Journal of Rock Mechanics and Engineering, vol. 30, no. 5, pp. 998-1006, 2011.

[15] D. G. Roy, T. N. Singh, J. Kodikara, and R. Das, "Effect of water saturation on the fracture and mechanical properties of sedimentary rocks," Rock Mechanics and Rock Engineering, vol. 50, pp. 2585-2600, 2017.

[16] N. Li, H. Xu, and B. Hu, "Shear creep characteristics of sandstone under dry and saturated states," Rock and Soil Mechanics, vol. 33, no. 2, pp. 439-443, 2012.

[17] Z. A. Erguler and R. Ulusay, "Water-induced variations in mechanical properties of clay-bearing rocks," International Journal of Rock Mechanics and Mining Sciences, vol. 46, no. 2, pp. 355-370, 2009.

[18] M. S. Shao, L. Li, and Z. X. Li, "Elastic wave velocity and mechanical properties of sandstone under different water contents at longyou grottoes," Chinese Journal of Rock Mechanics and Engineering, vol. 29, pp. 3514-3518, 2010.

[19] D. H. Yu and J. B. Peng, "Experimental study of mechanical properties of chlorite schist with water under triaxial compression," Chinese Journal of Rock Mechanics and Engineering, vol. 28, no. 1, pp. 205-211, 2009.

[20] J. Q. Guo, X. L. Liu, and C. S. Qiao, "Experimental study of mechanical properties and energy mechanism of karst limestone under natural and saturated states," Chinese Journal of Rock Mechanics and Engineering, vol. 33, no. 2, pp. 296308, 2014.

[21] J. Hadizadeh and R. D. Law, "Water-weakening of sandstone and quartzite deformed at various stress and strain rates," International Journal of Rock Mechanics and Mining Sciences \& Geomechanics Abstracts, vol. 28, no. 5, pp. 431-439, 1991.

[22] C. H. Yang, H. J. Mao, X. C. Wang, X. H. Li, and J. W. Chen, "Study on variation of microstructure and mechanical properties of water-weakening slates," Rock and Soil Mechanics, vol. 27, no. 12, pp. 2090-2098, 2006.

[23] W. B. Han, G. Zhou, Q. T. Zhang et al., "Experimental study on modification of physicochemical characteristics of acidified coal by surfactants and ionic liquids," Fuel, vol. 266, no. 4, pp. 1-12, 2020.

[24] W. Han, G. Zhou, D. Gao et al., "Experimental analysis of the pore structure and fractal characteristics of different metamorphic coal based on mercury intrusion-nitrogen adsorption porosimetry," Powder Technology, vol. 362, pp. 386-398, 2020.

[25] W. B. Han, G. Zhou, M. Y. Xing et al., "Experimental investigation on physicochemical characteristics of coal treated with synthetic sodium salicylate-imidazole ionic liquids," Journal of Molecular Liquids, Article ID 114822, 2020, in press.

[26] H. W. Huang and P. Che, "Research on micro-mechanism of softening and argillitization of mudstone," Journal of Tongji University (Natural Science), vol. 35, no. 7, pp. 866-870, 2007.

[27] Z. P. Meng, J. N. Pan, L. L. Liu, G. X. Meng, and Z. H. Zhao, "Influence of moisture contents on mechanical properties of sedimentary rock and its bursting potential," Chinese Journal of Rock Mechanics and Engineering, vol. 28, pp. 2637-2643, 2009. 
[28] B. Li, Study on rock failure characteristics and rock strength criteria under high confining pressure, $\mathrm{PhD}$ Dissertation, Wuhan University of Science and Technology, Wuhan, China, 2015.

[29] H. P. Xie, F. Gao, and Y. Ju, "Research and development of rock mechanics in deep ground engineering," Chinese Journal of Rock Mechanics and Engineering, vol. 34, no. 11, pp. 2161-2178, 2015.

[30] H. W. Zhou, H. P. Xie, and J. P. Zuo, "Developments in researches on mechanical behaviors of rocks under the condition of high ground pressure in the depths," Advance in Mechanics, vol. 35, no. 1, pp. 91-99, 2005.

[31] X. P. Zhou, Q. H. Qian, and H. Q. Yang, "Strength criteria of deep rock mass," Chinese Journal of Rock Mechanics and Engineering, vol. 27, no. 1, pp. 117-123, 2008.

[32] H. Li, B. Lai, and H. Liu, "Determination of tensile elastic parameters from Brazilian tensile test: theory and experiments," Rock Mechanics and Rock Engineering, vol. 52, no. 8, pp. 2551-2568, 2019.

[33] M. Y. Ren, Study on mechanism of collaborative bearing effect of rock- support system in deep tunnel construction, $\mathrm{PhD}$ Dissertation, Shandong University, Jinan, China, 2020.

[34] M. Y. Ren, Q. Y. Zhang, S. Y. Chen et al., "Physical model test study on synergistic action of lining-rock for deep tunnel under complex geological conditions," vol. 52, no. 8, pp. 98-109, 2019.

[35] X. T. Zhang, Q. Y. Zhang, S. B. Yuan, C. Wang, and Q. Gao, "Development of test device for direct axial tension on rock and its application," Chinese Journal of Rock Mechanics and Engineering, vol. 33, no. 12, pp. 2517-2523, 2014.

[36] The Professional Standards Compilation Group of People's Republic of China, Code for Rock Tests of Hydroelectric and Water Conservanty Engineering, China Electric Power Press, Beijing, China, 2007.

[37] Y. L. Lu, L. G. Wang, F. Yang, Y. J. Li, and H. M. Chen, "Postpeak strain softening mechanical properties of weak rock," Chinese Journal of Rock Mechanics and Engineering, vol. 29, no. 3, pp. 640-648, 2010.

[38] C. Sun, X. M. N. Hui, and Q. Zhang, "Study on the post peak strain softening behavior of mudstone and the interaction between surrounding rock and supporting structure," Journal of China University of Mining \&. Technology, vol. 45, no. 2, pp. 254-260, 2016.

[39] H. L. Liu, W. C. Zhu, Y. J. Yu, T. Xu, R. F. Li, and X. G. Liu, "Effect of water imbibition on uniaxial compression strength of sandstone," International Journal of Rock Mechanics \& Mining Sciences, vol. 127, no. 7, 2020.

[40] E. Hoek and E. T. Brown, Underground Excavations in Rock, CRC Press, Boca Raton, FL, USA, 1980.

[41] E. Hoek, "Hoek-Brown failure criterion-2002 edition," in Proceedings of the Fifth North American Rock Mechanics Symposium, vol. 1, pp. 18-22, Toronto, Canada, July 2002.

[42] N. Bahrani and P. K. Kaiser, "Strength degradation of nonpersistently jointed rockmass," International Journal of Rock Mechanics and Mining Sciences, vol. 62, pp. 28-33, 2013.

[43] J. C. Jin, C. X. She, and P. Y. Shang, "Study on strain-softening model for rock based on the Hoek-Brown criterion," Rock and Soil Mechanics, vol. 41, no. 3, pp. 939-951, 2020.

[44] G. Walton, D. Labrie, and L. R. Alejano, "On the residual strength of rocks and rockmasses," Rock Mechanics and Rock Engineering, vol. 52, no. 11, pp. 4821-4833, 2019.

[45] Y. Zhu, H. Zhou, C. Q. Zhang, and T. Lv, "Brittle inequality of Hoek-Brown criterion and it's applicability limit to GSI," Chinese Journal of Rock Mechanics and Engineering, vol. 38, pp. 3412-3419, 2019. 